\title{
Recovery of phospho-ERK activity allows melanoma cells to escape from BRAF inhibitor therapy
}

\author{
KHT Paraiso', IV Fedorenko', LP Cantini', AC Munko', M Hall', VK Sondak ${ }^{2}$, JL Messina ${ }^{3}$, KT Flaherty ${ }^{4}$ and \\ KSM Smalley*,1,2,5
}

'Department of Molecular Oncology, The Moffitt Cancer Center and Research Institute, I 2902 Magnolia Drive, Tampa, FL 336 I 2, USA; 'Department of Cutaneous Oncology, The Moffitt Cancer Center and Research Institute, I 2902 Magnolia Drive, Tampa, FL 336 I2, USA; ${ }^{3}$ Department of Pathology and Cell Biology, University of South Florida College of Medicine, 12901 Bruce B. Downs Boulevard, MDC II, Tampa, FL 336 I2, USA; ${ }^{4}$ Department of Medicine, Division of Hematology/Oncology, Massachusetts General Hospital Cancer Center, 55 Fruit Street, Yawkey 9E, Boston, MA 021 I4, USA;

${ }^{5}$ Department of Integrated Mathematical Oncology, The Moffitt Cancer Center and Research Institute, I 2902 Magnolia Drive, Tampa, FL 336 I2, USA

BACKGROUND: Resistance to BRAF inhibitors is an emerging problem in the melanoma field. Strategies to prevent and overcome resistance are urgently required.

METHODS: The dynamics of cell signalling, BrdU incorporation and cell-cycle entry after BRAF inhibition was measured using flow cytometry and western blot. The ability of combined BRAF/MEK inhibition to prevent the emergence of resistance was demonstrated by apoptosis and colony formation assays and in 3D organotypic cell culture.

RESULTS: BRAF inhibition led to a rapid recovery of phospho-ERK (pERK) signalling. Although most of the cells remained growth arrested in the presence of drug, a minor population of cells retained their proliferative potential and escaped from BRAF inhibitor therapy. A function for the rebound PERK signalling in therapy escape was demonstrated by the ability of combined BRAF/MEK inhibition to enhance the levels of apoptosis and abrogate the onset of resistance.

CONCLUSION: Combined BRAF/MEK inhibition may be one strategy to prevent the emergence of drug resistance in BRAF-V600Emutated melanomas.

British Journal of Cancer (2010) I 02, I724- 1730. doi:I0.1038/sj.bjc.66057|4 www.bjcancer.com

(C) 2010 Cancer Research UK

Keywords: melanoma; BRAF; resistance; therapy

The discovery that $\sim 50 \%$ of human melanomas harbour activating V600E mutations in the serine/threonine kinase BRAF has raised the possibility that these tumours may be amenable to targeted therapy (Davies et al, 2002; Smalley and Flaherty, 2009). A large number of preclinical studies have now validated mutated $B R A F$ as a bona fide therapeutic target in melanoma (Hingorani et al, 2003; Karasarides et al, 2004; Sharma et al, 2005). Mechanistically, mutated BRAF seems to exert most of its oncogenic effects through the activation of the RAF/MEK/ERK mitogen-activated protein kinase (MAPK) pathway (Karasarides et al, 2004; Wellbrock et al, 2004b). The MAPK activity drives the uncontrolled growth of melanoma cells by upregulating the expression of cyclin D1 and through the suppression of the cyclin-dependent kinase inhibitor p27 ${ }^{\mathrm{KIP} 1}$ (Smalley, 2003; Bhatt et al, 2005).

A number of novel BRAF inhibitors have been described that are now at various stages of clinical development (King et al, 2006; Montagut et al, 2008; Tsai et al, 2008; Flaherty et al, 2009). Of these, PLX4032 and PLX4720 (Plexxikon/Roche, Nutley, NJ, USA), have been exciting great interest, with recent studies from our group and others showing these compounds to have excellent anti-tumour activity in vitro and in vivo (Cartlidge et al, 2008; Sala

*Correspondence: Dr KSM Smalley; E-mail: keiran.smalley@moffitt.org Received 29 April 20I0; revised 6 May 20I0; accepted 10 May 2010 et al, 2008; Tsai et al, 2008). PLX4032 has been recently evaluated in a phase I clinical trial of melanoma patients harbouring the $B R A F-V 600 \mathrm{E}$ mutation (Flaherty et al, 2009). Responses were observed in an unprecedented $70 \%$ of patients, and there is now hope that small molecule BRAF inhibitors could constitute a major new melanoma therapy.

Although the clinical development of BRAF inhibitors is at an early stage, it is already clear that the impressive levels of response seen initially do not necessarily persist for extended periods of time. These observations mirror the pattern of response seen to targeted therapy in CML, GIST (Sawyers, 2004; Bauer et al, 2007) and most recently medulloblastoma (Rudin et al, 2009; Yauch et al, 2009), where an initial period of tumour regression is later followed by relapse. In this study, we have identified the rebound activation of phospho-ERK (pERK) as being a mechanism of early therapy escape and show that combined BRAF/MEK inhibition can both enhance the levels of apoptosis and abrogate the onset of resistance.

\section{MATERIALS AND METHODS}

\section{Cell culture and growth inhibition}

Melanoma cell lines were a gift from Dr Meenhard Herlyn (The Wistar Institute) and were genotyped as described in 
Haass et al (2008). Cells were plated into a 96-well plate at a density of $2.5 \times 10^{4}$ cells per $\mathrm{ml}$ and left to grow overnight before being treated with increasing concentrations of PLX4720 in triplicate; after $72 \mathrm{~h}$, the levels of growth inhibition were examined using the MTT assay (Smalley et al, 2007b). Data show the mean of at least three independent experiments \pm the s.e. mean. In all cases, * indicates statistical significance where $P<0.05$. PLX4720 was dissolved in $100 \%$ DMSO and stored at $-20^{\circ} \mathrm{C}$ as a $10 \mathrm{~mm}$ solution. U0126 was from EMD Biosciences (Carlsbad, CA, USA) and was prepared in a similar manner to PLX4720.

\section{Western blotting}

Proteins were extracted and blotted for as described in Smalley et al (2005). After analysis, western blots were stripped once and reprobed for $\beta$-actin or GAPDH to demonstrate even protein loading. The antibodies to pERK, cleaved caspase-3, phospho-RB protein, total-RB protein, PARP, CRAF, cyclin D1 and total-ERK were from Cell Signaling Technology (Beverly, MA, USA) and the antibody to p27 was from BD Biosciences (Franklin Lakes, NJ, USA).

\section{Flow cytometry}

Cells were plated into $10-\mathrm{cm}$ dishes at $60 \%$ confluency and left to grow overnight before being treated with PLX4720 $(0.3$ and $3 \mu \mathrm{M})$ for $24 \mathrm{~h}$. In other studies, cells were treated with PLX4720 (3 $\mu \mathrm{M})$ in the absence or presence of U0126 (3 $\mu \mathrm{M})$ and harvested after 24 or $48 \mathrm{~h}$. Annexin-V labelling and propidium iodide staining were performed as described in Smalley et al (2007a).

\section{BrdU incorporation}

Cells were seeded in $10 \mathrm{~cm}$ plates at a density of $100000 \mathrm{cells} \mathrm{ml}^{-1}$ and grown overnight before being treated with PLX4720 $(3 \mu \mathrm{M})$ for $72 \mathrm{~h}$ or 1, 2, 3 and 4 weeks. For the 1-, 2-, 3- and 4-week treatments, PLX4720 $(3 \mu \mathrm{M})$ was added twice per week. One hour before the end of the drug treatment, BrdU (Sigma-Aldrich, St Louis, MO, USA) was added to the cells to a final concentration of $20 \mu \mathrm{M}$ for $1 \mathrm{~h}$. Cells were fixed and permeabilised with eBioscience's fixation and permeabilisation buffers. The BrdU epitopes were exposed by incubating with DNase (Sigma-Aldrich) before staining with anti-BrdU conjugated to FITC (eBioscience, San Diego, CA, USA). In all, 7-AAD (BD Bioscience) was added to stain for DNA before acquisition on a BD Facscalibur flow cytometer.

\section{MEK1 sequencing}

Sequencing of MEK1 Exons 3 and 6 was performed as described in Emery et al (2009).

\section{D spheroid assays}

Melanoma spheroids were prepared using the liquid overlay method (Smalley et al, 2006). Spheroids were treated with $0.03-30 \mu \mathrm{M}$ of PLX4720 or U0126, PLX4720 (both $3 \mu \mathrm{M}$ ) and both drugs in combination for $72 \mathrm{~h}$ before being washed $(3 \times$ in media) and treated with calcein-AM, ethidium bromide (Molecular Probes, Eugene, OR, USA) for $1 \mathrm{~h}$ at $37^{\circ} \mathrm{C}$, according to the manufacturer's instructions. After this time, pictures of the invading spheroids were taken using a Nikon-300 inverted fluorescence microscope.

\section{Colony formation}

Cells $\left(1 \times 10^{4}\right.$ per $\left.\mathrm{ml}\right)$ were seeded out into six-well plates and grown overnight before being treated with vehicle, PLX4720 $(3 \mu \mathrm{M})$, U0126 $(3 \mu \mathrm{M})$ or the two drugs in combination. Cells were left to grow for 4 weeks with new drug added twice per week. Media was aspirated, and plates were stained with crystal violet solution $\left(50 \%\right.$ methanol $+50 \% \mathrm{H}_{2} \mathrm{O}+0.5 \%$ crystal violet $)$. Control plates were grown for 1 week in the absence of any drug, until $100 \%$ confluency was reached.

\section{RESULTS}

\section{PLX4720 has selective effects on BRAF-V600E-mutated melanoma cell lines}

Treatment of melanoma cells with increasing concentrations of the BRAF inhibitor PLX4720 led to a dose-dependent reduction in the growth of BRAF-V600E-mutated melanoma cell lines (WM35, WM164 and 1205Lu) (Figure 1A). In contrast, cell lines that harboured an NRAS mutation (WM1346, WM1361A and WM1366) were more resistant (Figure 1A). Lower doses of PLX4720 (0.3 and $3 \mu \mathrm{M}$ ) led to a profound G1-phase cell-cycle arrest and a reduction of $1205 \mathrm{Lu}$ cells entering into S-phase (Figure 1B). Increasing concentrations of PLX4720 ( $1 \mathrm{~h})$ inhibited pERK signalling in three $B R A F$-mutated melanoma cell lines (WM35, WM164 and 1205Lu), but not an NRAS-mutated cell line (WM1346) (Figure 1C). It was noted that PLX4720 also reduced pRB protein phosphorylation, increased p27 expression, suppressed cyclin D1 expression and induced cleavage of PARP only in melanoma cell lines harbouring the BRAF-V600E mutation (Figure 1D).

\section{PLX4720-mediated apoptosis induction is $B R A F-V 600 \mathrm{E}-\mathrm{mutation}$ specific}

Concentrations of PLX4720 $\geqslant 3 \mu \mathrm{M}$ were required for apoptosis induction across a panel of three $B R A F$-mutated melanoma cell lines (WM35, WM164 and 1205Lu) (Figure 2A). The pro-apoptotic effects of PLX4720 were found to be BRAF specific, with high levels ( $>30 \%$ ) of apoptosis only induced in the BRAF-V600E-mutated melanoma cell line panel (WM35, WM164 and 1205Lu), and not the NRAS-mutated melanoma cell lines (WM1346, WM1361A and WM1366) (Supplementary Figure 1). The induction of apoptosis was found to be time dependent with apoptosis observed only $>24 \mathrm{~h}$. Often, the pharmacological profile of drugs in 2D culture is not predictive of response in 3D culture. Here, it was found that the concentrations of PLX4720 required $(>3 \mu \mathrm{M})$ to induce apoptosis in 2D cell culture (Figure $2 \mathrm{~B}$ ) were equivalent to those necessary for loss of spheroid viability (as shown by the reduction of green staining and increased red staining) (Figure 2B). Interestingly, some viable melanoma cells persisted even at the highest concentrations of drug.

\section{Some cells escape from PLX4720 treatment and become resistant}

We next asked whether BRAF-V600E-mutated melanoma cells escaped from PLX4720 therapy and become drug resistant. Here, melanoma cell lines (WM164 and 1205Lu) were treated with PLX4720 (either 2 or $3 \mu \mathrm{M}$ ) over a 2-month period with fresh drug added twice per week. It was noted that after an initial round of cell death, a limited number of viable cells remained and as treatment progressed, these clones began to regrow ( $>28$ days) and eventually repopulated the whole culture (Figure $3 \mathrm{~A}$ ). The drugresistant phenotype of the surviving cells was demonstrated by the ability of both cell lines to maintain their pERK signalling and incorporate $\mathrm{BrdU}$ in the continuous presence of PLX4720 $(3 \mu \mathrm{M})$ (Figure $3 \mathrm{~B}$ and $\mathrm{C})$. In contrast, PLX4720 treatment $(3 \mu \mathrm{M})$ potently inhibited BrdU incorporation in the PLX4720-naive WM164 and $1205 \mathrm{Lu}$ cell lines (Figure 3C). It was further shown that the proliferation of the PLX4720-resistant WM164 and 1205Lu cell lines was dependent on MAPK signalling, with MEK inhibitor 

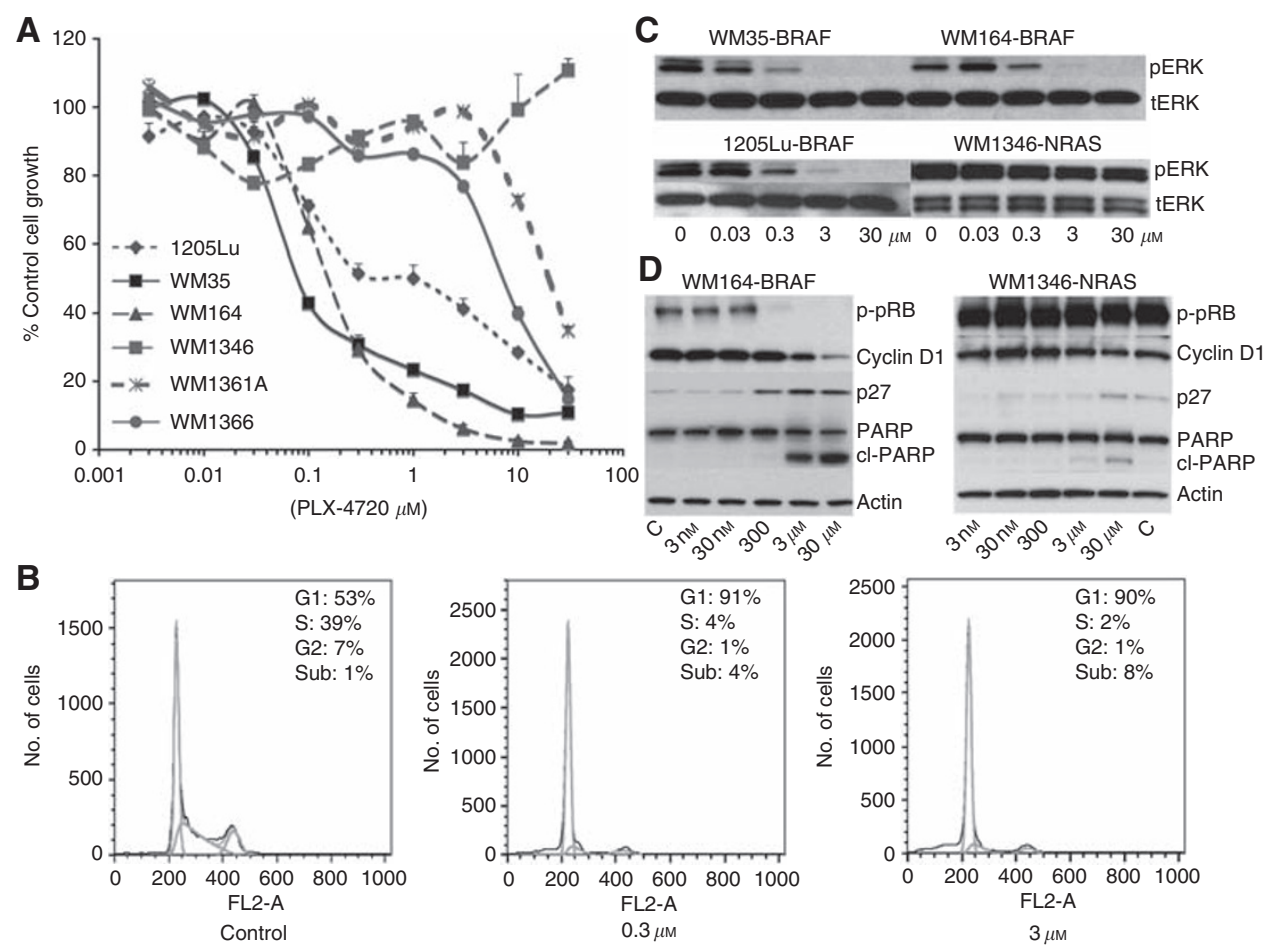

Figure I PLX4720 inhibits the growth of melanoma cells harbouring the BRAF-V600E mutation. (A). Increasing concentrations of PLX4720 reduced the growth of melanoma cell lines harbouring the BRAF-V600E mutation (WM35, I205Lu and WMI64), whereas melanoma cell lines that were BRAF wild type were relatively resistant $(\mathrm{WMI} 346, \mathrm{WMI} 36 \mathrm{IA}$ and $\mathrm{WMI} 366)$. Cells were treated with drug $(3 \mathrm{nM}-30 \mu \mathrm{M})$ for $72 \mathrm{~h}$, and cell numbers were quantified using the MTT assay. Bars show s.e. mean. (B) Low doses of PLX4720 are cytostatic in melanoma cells harbouring the BRAF-V600E mutation. I205Lu cells were treated were either 0.3 or $3 \mu \mathrm{M}$ PLX 4720 for $24 \mathrm{~h}$ before being fixed, stained with propidium iodide and analysed by flow cytometry. (C) PLX 4720 inhibits MAPK signalling in BRAF-V600E-mutated melanoma cells. Cells were treated with increasing concentrations of PLX4720 (0.03-30 $\mu \mathrm{M}$, I h); proteins were extracted and probed for expression of phospho-ERK (pERK). Blots were stripped once and reprobed for total-ERK to show even protein loading. (D) PLX4720 induces a concentration-dependent reduction in the phosphorylation of the retinoblastoma protein (phospho-RB), induces the cleavage of PARP, stabilises p27 and suppresses the expression of cyclin DI in WMI64 BRAF-V600E-mutated melanoma cells. Cells were treated with increasing concentrations of PLX4720 ( $3 \mathrm{nM}-30 \mu \mathrm{M})$ for $24 \mathrm{~h}$, after which time, protein was extracted and resolved by western blotting $(\mathrm{C}=$ vehicle control). Blots were stripped once and probed for actin to show equal protein loading.
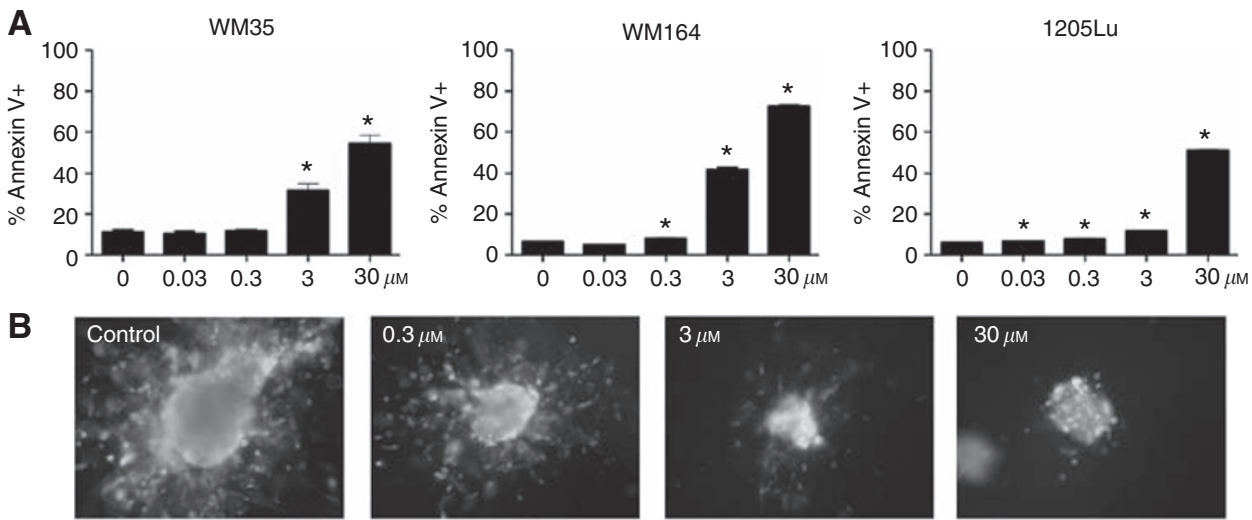

Figure 2 PLX4720 induces apoptosis in BRAF-V600E-mutated melanoma cell lines. (A) PLX4720 induces apoptosis in three BRAF-mutated melanoma cell lines. Cultures were treated with increasing concentrations of PLX4720 (0.03-30 $\mu \mathrm{M}, 48 \mathrm{~h})$, before staining for FITC-annexin-V and flow cytometry. Data show mean of three experiments. (B) PLX4720 reduces viability and invasion of I 205Lu cells grown as 3D collagen-implanted spheroids. Preformed I 205Lu spheroids were implanted into collagen and overlayed with media. Cells were treated with PLX4720 $(0.3-30 \mu \mathrm{M}$ for $72 \mathrm{~h})$ before being treated with calceinAM and ethidium bromide. Green, viable cells; red, dead cells. Lack of green staining also indicates a loss of cell viability. Magnification $\times 10$. $* P<0.05$, Significant difference from control. The colour reproduction of this figure is available on the html full text version of the manuscript.

treatment (U0126; 3 and $10 \mu \mathrm{M})$ preventing the incorporation of BrdU (Figure 3C).

Earlier studies have suggested that acquired resistance to the MEK inhibitor AZD6244 occurs as the result of an acquired mutation in MEK1 (Emery et al, 2009). As BRAF and MEK lie in the same signal transduction pathway, we sequenced Exons 3 and 6 of MEK1 for both WM164 and 1205Lu cell lines. It was found that neither of the PLX4720-resistant cell lines 


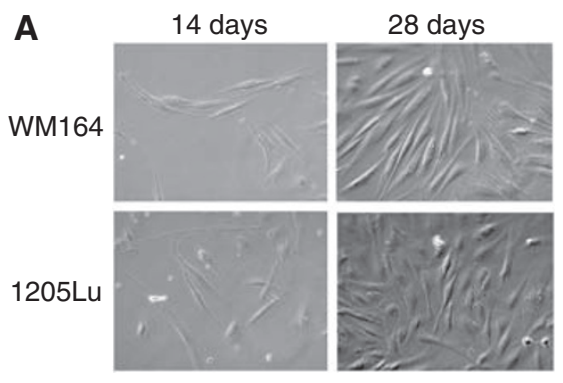

B

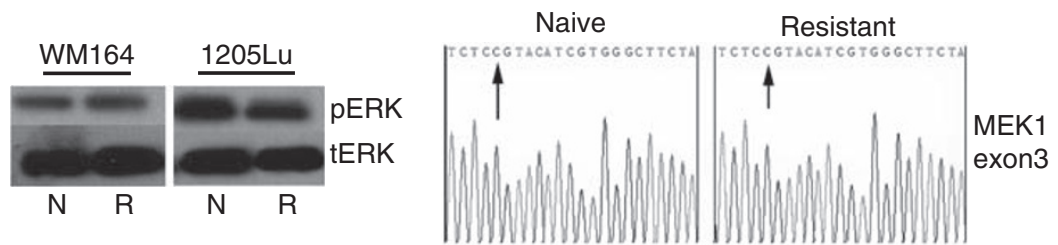

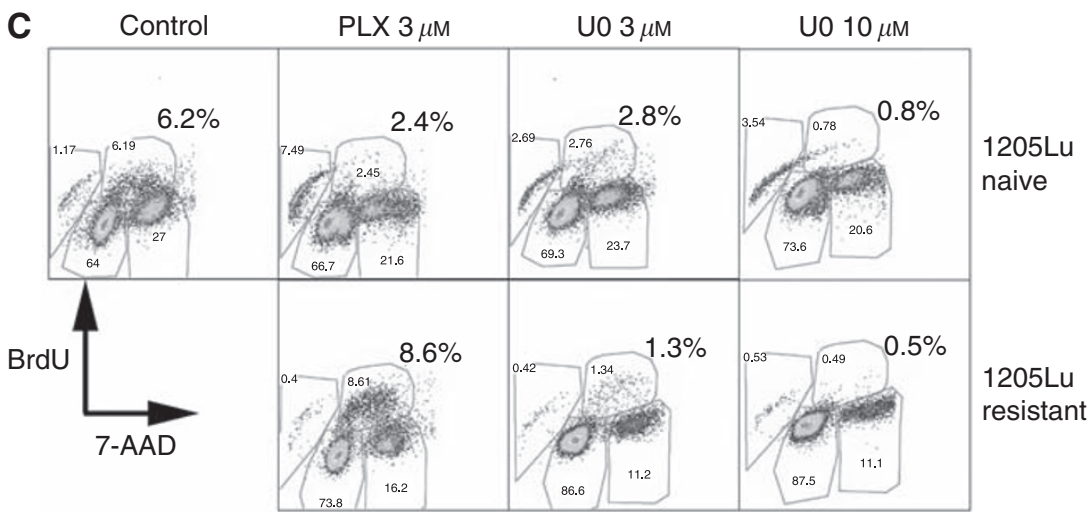

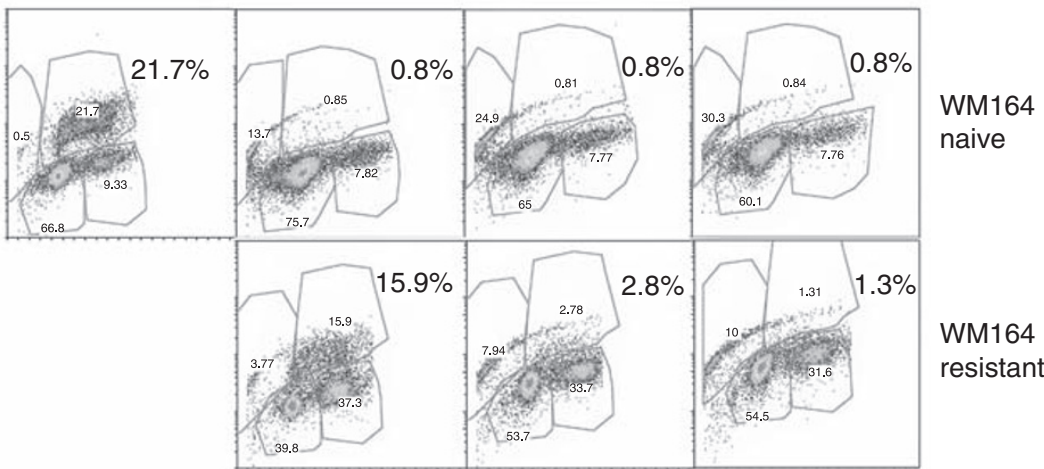

Figure 3 Melanoma cells escape PLX4720 and become resistant. (A) Representative photomicrograph of WMI64 and I205Lu melanoma cells treated with PLX4720 (3 $\mu \mathrm{M})$ for either 14 or 28 days. (B) Western blot showing levels of pERK expression in PLX4720 naive (N) and resistant (R) $(8$ weeks, $3 \mu \mathrm{M})$ WMI 64 and I205Lu cell lines. Note that the resistant cell lines were maintained continuously in the presence of PLX4720 (3 $\mu$ M). Total-ERK demonstrates even protein loading. (C) Resistant I205Lu and WMI 64 cell lines continue to incorporate BrdU in the continual presence of PLX4720 (3 $\mu$ M). Panel shows either treatment-naive WMI 64 and 1205Lu cell lines (control) or resistant (chronically treated with PLX4720 for 8 weeks) treated with either PLX4720 $(3 \mu \mathrm{M})$ or the MEK inhibitor U0 I 26 (3 and I0 $\mu \mathrm{M})$. Cells were stained for BrdU (20 $\mu \mathrm{M}, \mathrm{I}$ h) uptake and the cell viability marker 7-AAD and were analysed by flow cytometry. (D) Representative sequencing trace from Exon 3 of MEKI of I 205Lu cells chronically treated with PLX4720 for 8 weeks, arrow indicates site of PI24L mutation identified previously in Emery et al (2009).

acquired the P124L or Q56P mutations in MEK1 (Figure 3D and data not shown).

\section{Prolonged PLX4720 treatment leads to a recovery of pERK signalling}

Having shown the reliance of the PLX4720-resistant melanoma cell lines on MAPK signalling, we next investigated the time course of pERK signalling recovery. Treatment of drug-naive WM164 cells with PLX4720 $(3 \mu \mathrm{M})$ showed the pathway to be rapidly inhibited, with some recovery of signalling $>24 \mathrm{~h}$ (Figure $4 \mathrm{~A}$ and $\mathrm{B}$ ). The recovery of pERK signalling observed was found to be insensitive to repeated PLX4720 treatments (drug added every $24 \mathrm{~h}$ ) (Figure 4A). To explain the apparent anomaly between the recovery of pERK signalling $>24 \mathrm{~h}$ and the profound growth arrest/apoptosis observed at 48 and $72 \mathrm{~h}$ (Figures $1 \mathrm{~A}$ and $2 \mathrm{~A}$ ), we next investigated the cell cycle and signalling profile of cells treated with PLX4720 over a 72-h period. These studies showed that even though pERK signalling recovered, the majority of the cells remained growth arrested (Figure $4 \mathrm{C}$ ), and that this was associated with increased p27 expression and hypophosphorylation of the $\mathrm{pRB}$ protein (Figure 4D). Interestingly, a minor population of cells were identified that continued to proceed through S-phase (Figure 4C). The existence of a minor proliferating subpopulation was also confirmed by BrdU incorporation assays ( $1-4$ weeks), with studies showing that $2-4 \%$ of WM164 and WM793 cells continued to incorporate $\mathrm{BrdU}$ in the continuous presence of PLX4720 (3 $\mu \mathrm{M})$ (Supplementary Figure 2).

Cell counting experiments were performed to better understand how PLX4720-induced apoptosis, cell-cycle arrest and therapy escape impacted on the population as a whole (Figure 4E). It was observed that after an initial drop in cell numbers, the population remained relatively stable, suggesting that the recovery of pERK signalling attenuated the anti-melanoma activity of PLX4720. 
A

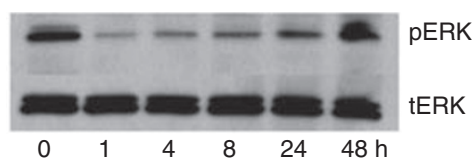

B WM164

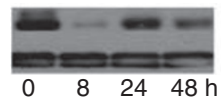

WM793

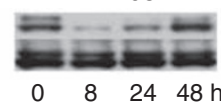

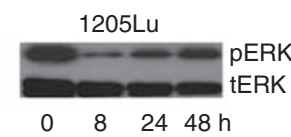

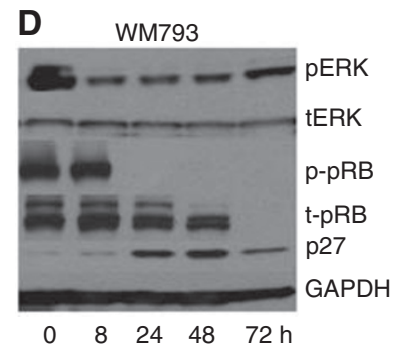

E
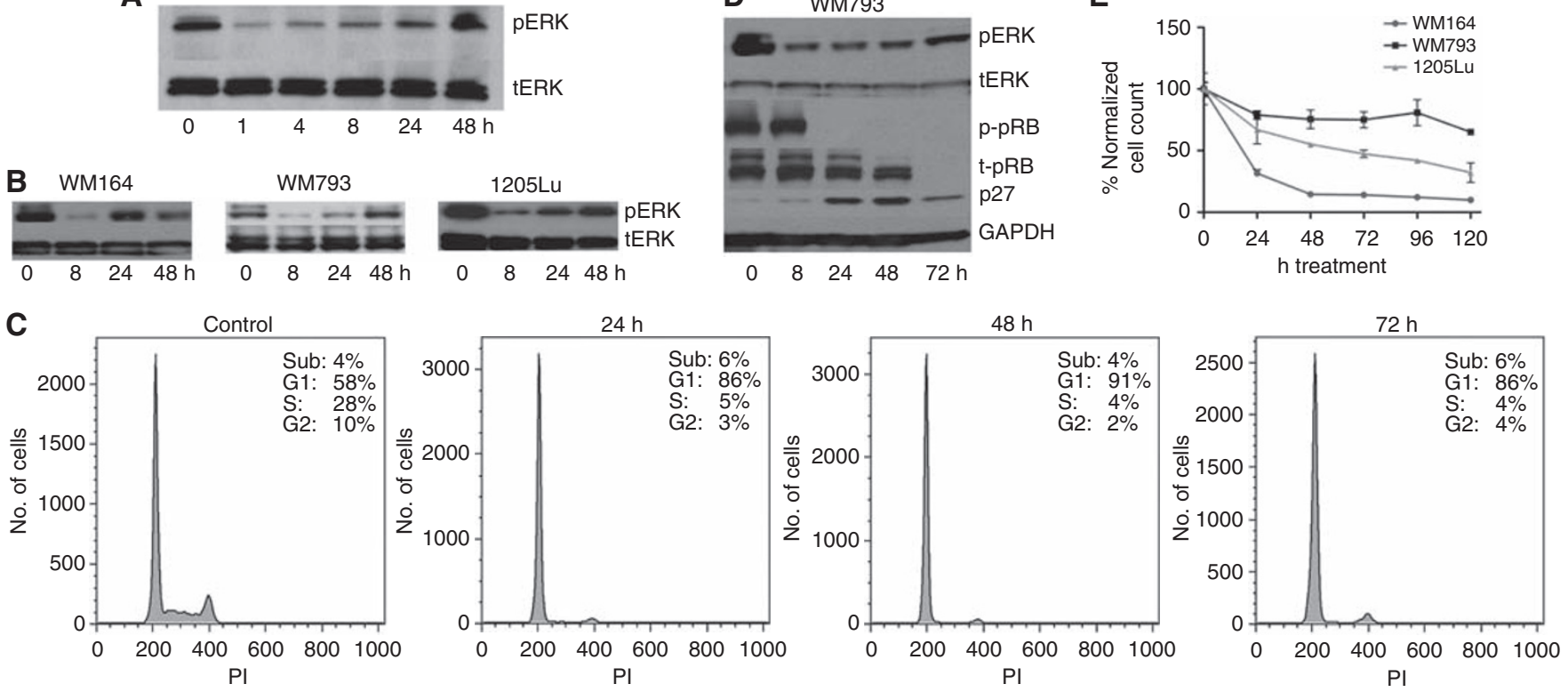

Figure 4 pERK signalling recovers after PLX4720 treatment. (A) Naive WMI 64 melanoma cells were treated with $P L X 4720(3 \mu M$, every $24 \mathrm{~h})$ for increasing periods of time $(0-48 \mathrm{~h})$ and probed for pERK and total-ERK (tERK). (B) Recovery of pERK is observed in three naive BRAF-V600E-mutated

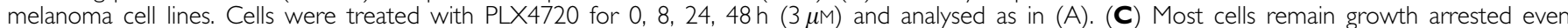
when pERK recovers. WM793 cells were treated with PLX4720 (3 $\mu \mathrm{M})$ for $0-72 \mathrm{~h}$. Cells were harvested, fixed and stained with propidium iodide before being analysed by flow cytometry. (D) p27 expression levels remain high even when pERK signalling recovers. WM793 cells were treated with PLX4720 as for $(\mathbf{C})$; protein lysates were probed for expression of pERK, total-ERK (tERK), phospho-RB ( $p-p R B$ ), total retinoblastoma protein (t-RB) and p27. Equal protein loading was confirmed by stripping the blot once and probing for GAPDH expression. (E) PLX4720 treatment leads to a drop in cell numbers followed by stabilisation of the population. WM793, I205Lu and WMI 64 melanoma cells were treated with PLX4720 (3 $\mu$ M) for 0- I20 h. At each time point, the cells were removed from the plate and counted. Data show the mean \pm s.e.mean of three independent experiments.

\section{Rebound pERK treatment allows for escape from PLX4720-mediated apoptosis}

Having demonstrated that pERK signalling recovered after PLX4720 treatment, we next determined whether dual BRAF/ MEK inhibition led to enhanced cytotoxicity. It was noted that although the recovery of pERK signalling was insensitive to repeated PLX4720 treatments (Figure 4A), rebound pERK signalling was sensitive to the MEK inhibitor U0126 $(3 \mu \mathrm{M})$ (Figure 5A and B). Combined treatment of drug-naive WM164 cells with both PLX4720 and U0126 was found to decrease the expression of cyclin D1 (Figure 5C) and enhance the level of PLX4720-induced PARP and caspase-3 cleavage (Figure 5C). In contrast, expression of p27, a protein relatively sensitive to BRAF/MEK inhibition, was little enhanced when PLX4720 and U0126 were combined. The western blotting results were also mirrored in apoptosis assays, with the addition of U0126 (3 $\mu \mathrm{M})$ significantly enhancing the pro-apoptotic activity of low-dose PLX4720 $(3 \mu \mathrm{M})$ in drug-naive WM164 cells at both 24 and $48 \mathrm{~h}$ (Figure 5D).

\section{Combined BRAF/MEK inhibitor treatment prevents the acquisition of resistance}

In a final series of experiments, we explored whether dual BRAF/MEK inhibition blocked the MAPK-dependent escape from PLX4720 therapy and asked whether this prevented the onset of resistance. Here, WM164, WM793 and 1205Lu cells were treated with PLX4720 $(3 \mu \mathrm{M})$, U0126 $(3 \mu \mathrm{M})$ or the two inhibitors in combination for 4 weeks. It was noted that although PLX4720 was more effective at reducing colony formation than U0126 (Figure 6A), a number of clones did remain. In contrast, treatment with U0126 and PLX4720 in combination completely inhibited the formation of all colonies. A thorough microscopic examination of the plates revealed that no cells remained (Figure 6A, see inset). Examination of the vehicle control plates showed the cells to be highly confluent. It was further found that the combination of PLX4720 and U0126 (both $3 \mu \mathrm{M}$ ) also reduced the growth and survival of melanoma cell lines grown as 3D collagen-implanted spheroid cultures (Figure 6B).

\section{DISCUSSION}

The past 30 years have seen little improvement in the treatment of disseminated melanoma. After the recent success of targeted therapy agents such as imatinib mesylate in chronic myeloid leukemia, there is now hope that melanoma may be amenable to similar strategies. A recent phase I clinical trial of the BRAF inhibitor PLX4032 has validated this concept and showed that most patients whose melanomas harboured the BRAF V600E respond well to this treatment (Flaherty et al, 2009). Although long-term follow-up data are not currently available, early indications suggest that most PLX4032-treated patients eventually become resistant. In this study, we have focused on the earliest stages of therapy escape after treatment with the BRAF inhibitor PLX4720. Through an initial series of experiments, we confirmed that PLX4720 had good selectivity for BRAFmutated melanoma cell lines over those harbouring NRAS mutations and also demonstrated that PLX4720 was able to induce significant levels of apoptosis. The induction of apoptosis induced was slow in onset $(>24 \mathrm{~h})$, but very $B R A F$ specific, with very little apoptosis observed in melanoma cell lines that were $B R A F$ wild type.

Currently, very little is known about the mechanism of early therapy escape after BRAF inhibition. In non-melanoma systems, 
A

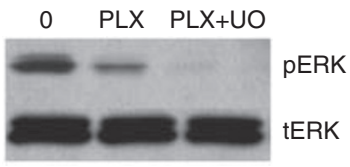

B

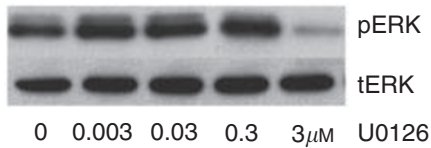

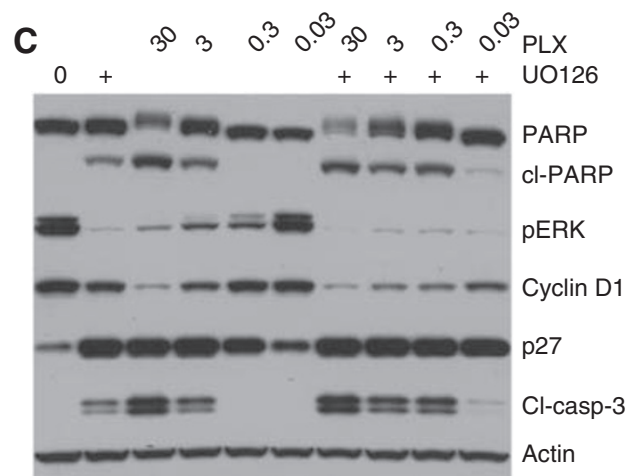

D

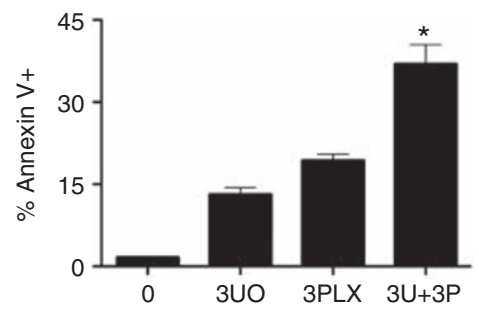

Figure 5 The function of rebound PERK signalling in the escape from PLX4720 treatment. (A) U0I26 blocks the rebound increase in pERK after PLX4720 treatment. Melanoma cells were either treated with vehicle (0), PLX4720 (3 $\mu \mathrm{M})$ or PLX4720 + U0I26 (both $3 \mu \mathrm{M}$ ) for $48 \mathrm{~h}$, protein was then probed for expression of pERK and tERK. (B) Melanoma cells were treated with increasing concentrations of $U 0 \mathrm{I} 26$ for I h before being probed for pERK and tERK expression. (C) Cells were treated with increasing concentrations of PLX4720 (30 nM-30 $\mu \mathrm{M})$ for $24 \mathrm{~h}$ in the absence or presence of U0 I 26 $(3 \mu \mathrm{M})$, after which time, protein was extracted and resolved by western blotting and probed for either cleaved PARP (cl-PARP), phospho-ERK (pERK), cyclin DI (Cyclin DI), p27 or cleaved caspase-3 (cl-casp-3). Blots were stripped once and probed for actin to show equal protein loading. (D) Combined BRAF and MEK inhibition leads to enhanced apoptosis. WMI 64 cells were treated with either vehicle, U0I26 ( $3 \mu \mathrm{M}, 3 \cup 0)$. PLX4720 (3PLX, $3 \mu \mathrm{M})$ or the two inhibitors in combination for $48 \mathrm{~h}$. Levels of apoptosis were measured by annexin- $V$ staining and flow cytometry. Data show the mean of three experiments. $* P<0.05$

A
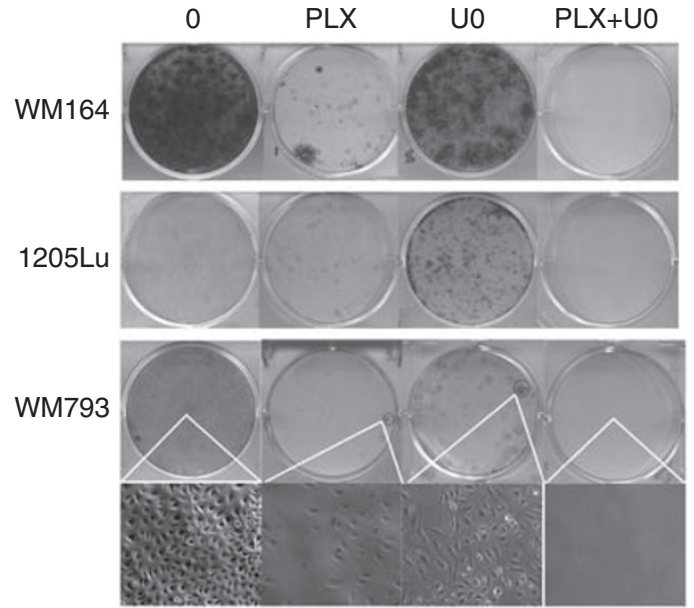

B

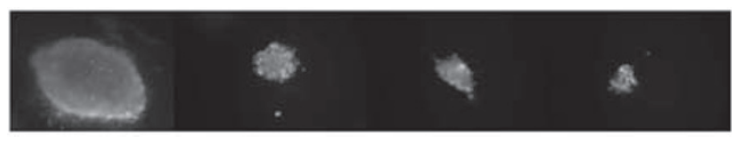

Control

PLX

UO

$\mathrm{UO}+\mathrm{PLX}$

Figure 6 Dual BRAF/MEK inhibition prevents escape from PLX4720 therapy. (A) WMI 64, WM793 and I205Lu melanoma cells were treated with vehicle (I week), PLX4720 (3 $\mu \mathrm{M})$, U0I26 (3 $\mu \mathrm{M})$ or the two inhibitors in combination (both $3 \mu \mathrm{M}$ ) for 4 weeks. After this time, colonies were fixed and stained with crystal violet. Photographs are representative of three independent experiments. Photomicrographs show the detail of one colony each on the WM793 plate $(\times 4)$. (B) Combined PLX4720 and U0 126 treatment reduce growth of melanoma cells and enhance cell death in a 3D spheroid model. WMI 64 spheroids were implanted in collagen and treated with PLX4720 $(3 \mu \mathrm{M})$, U0I26 $(3 \mu \mathrm{M})$ or the two drugs in combination for $72 \mathrm{~h}$. After this time, plates were washed and cells were stained with a cell viability kit. Red=dead cells, green $=$ live cells. The colour reproduction of this figure is available on the html full text version of the manuscript. chronic treatment with the MEK inhibitor CI-1040 leads to resistance associated with increased KRAS and MEK expression (Wang et al, 2005). In melanoma, it has been shown that both growth factors and cytokines rescue cells from apoptosis after siRNA-induced knockdown of BRAF (Christensen and Guldberg, 2005; Gray-Schopfer et al, 2007). Recent work has also suggested that resistance of melanoma patients to the MEK inhibitor AZD6244 is associated with mutations in MEK1 (Emery et al, 2009). Other studies have shown that acquired BRAF inhibitor resistance after long-term drug treatment is associated with pathway switching, where MAPK signalling is routed from BRAF to CRAF (Montagut et al, 2008).

This study makes the unexpected observation that combined BRAF and MEK inhibitor treatment enhances the levels of apoptosis before resistance to BRAF inhibition is even acquired, suggesting that the recovery of melanoma signalling occurs much earlier than previously suspected. The observation that dual MEK/BRAF inhibition blocks colony formation also argues that rebound MAPK signalling observed has a key function in the escape from therapy. Although targeting the same pathway at two points seems redundant, it is likely that dual inhibition may be a good strategy to counteract the feedback inhibition loops that are relieved after pathway blockade at a single point (Pratilas et al, 2009). Intriguingly, the possibility also exists that MEK and BRAF inhibitors may hit subtly different cellular targets. There is already evidence that both ARAF and CRAF affect pathways other than MEK, and although not well characterised, it is possible that other BRAF targets may exist (Wellbrock et al, 2004a).

The finding that dual BRAF/MEK inhibition prevents the onset of resistance in our in vitro melanoma models suggests that MEK inhibitors may be of use in managing resistance to BRAF inhibitors and may delay or even prevent the onset of resistance in some cases. These findings provide a strong rationale for the testing of combined BRAF and MEK inhibitors in the clinical setting. 


\section{ACKNOWLEDGEMENTS}

We thank Gideon Bollag at Plexxikon Inc. for providing the PLX4720. This study was supported by the Melanoma Research Foundation, the Bankhead-Coley Research Program of the State of Florida (09BN-14), an Institutional Research Grant from the American Cancer Society 93-032-13, a Career Development

\section{REFERENCES}

Bauer S, Duensing A, Demetri GD, Fletcher JA (2007) KIT oncogenic signaling mechanisms in imatinib-resistant gastrointestinal stromal tumor: PI3-kinase/AKT is a crucial survival pathway. Oncogene 26: $7560-7568$

Bhatt KV, Spofford LS, Aram G, McMullen M, Pumiglia K, Aplin AE (2005) Adhesion control of cyclin D1 and p27Kip1 levels is deregulated in melanoma cells through BRAF-MEK-ERK signaling. Oncogene 24: $3459-3471$

Cartlidge RA, Thomas GR, Cagnol S, Jong KA, Molton SA, Finch AJ, McMahon M (2008) Oncogenic BRAF(V600E) inhibits BIM expression to promote melanoma cell survival. Pigment Cell Melanoma Res 21: $534-544$

Christensen C, Guldberg P (2005) Growth factors rescue cutaneous melanoma cells from apoptosis induced by knockdown of mutated (V 600 E) B-RAF. Oncogene 24: 6292-6302

Davies H, Bignell GR, Cox C, Stephens P, Edkins S, Clegg S, Teague J, Woffendin H, Garnett MJ, Bottomley W, Davis N, Dicks E, Ewing R, Floyd Y, Gray K, Hall S, Hawes R, Hughes J, Kosmidou V, Menzies A, Mould C, Parker A, Stevens C, Watt S, Hooper S, Wilson R, Jayatilake H, Gusterson BA, Cooper C, Shipley J, Hargrave D, Pritchard-Jones K, Maitland N, Chenevix-Trench G, Riggins GJ, Bigner DD, Palmieri G, Cossu A, Flanagan A, Nicholson A, Ho JW, Leung SY, Yuen ST, Weber BL, Seigler HF, Darrow TL, Paterson H, Marais R, Marshall CJ, Wooster R, Stratton MR, Futreal PA (2002) Mutations of the BRAF gene in human cancer. Nature 417: 949 - 954

Emery CM, Vijayendran KG, Zipser MC, Sawyer AM, Niu L, Kim JJ, Hatton C, Chopra R, Oberholzer PA, Karpova MB, Macconaill LE, Zhang J, Gray NS, Sellers WR, Dummer R, Garraway LA (2009) MEK1 mutations confer resistance to MEK and B-RAF inhibition. Proc Natl Acad Sci USA 106: $20411-20416$

Flaherty KT, Puzanov I, Sosman JA, Kim K, Ribas A, McArthur G, Lee RJ, Grippo JF, Nolop K, Chapman PB (2009) Phase I study of PLX4032: proof of concept for V600E BRAF mutation as a therapeutic target in human cancer. J Clin Oncol 27. Abstract 9000

Gray-Schopfer VC, Karasarides M, Hayward R, Marais R (2007) Tumor necrosis factor-alpha blocks apoptosis in melanoma cells when BRAF signaling is inhibited. Cancer Res 67: $122-129$

Haass NK, Sproesser K, Nguyen TK, Contractor R, Medina CA, Nathanson KL, Herlyn M, Smalley KS (2008) The mitogen-activated protein/extracellular signal-regulated kinase kinase inhibitor AZD6244 (ARRY-142886) induces growth arrest in melanoma cells and tumor regression when combined with docetaxel. Clin Cancer Res 14: $230-239$

Hingorani SR, Jacobetz MA, Robertson GP, Herlyn M, Tuveson DA (2003) Suppression of BRAF(V599E) in human melanoma abrogates transformation. Cancer Res 63: 5198-5202

Karasarides M, Chiloeches A, Hayward R, Niculescu-Duvaz D, Scanlon I, Friedlos F, Ogilvie L, Hedley D, Martin J, Marshall CJ, Springer CJ, Marais R (2004) B-RAF is a therapeutic target in melanoma. Oncogene 23: $6292-6298$

King AJ, Patrick DR, Batorsky RS, Ho ML, Do HT, Zhang SY, Kumar R, Rusnak DW, Takle AK, Wilson DM, Hugger E, Wang L, Karreth F, Lougheed JC, Lee J, Chau D, Stout TJ, May EW, Rominger CM, Schaber MD, Luo L, Lakdawala AS, Adams JL, Contractor RG, Smalley KS, Herlyn M, Morrissey MM, Tuveson DA, Huang PS (2006) Demonstration of a genetic therapeutic index for tumors expressing oncogenic BRAF by the kinase inhibitor SB-590885. Cancer Res 66: $11100-11105$

Montagut C, Sharma SV, Shioda T, McDermott U, Ulman M, Ulkus LE, Dias-Santagata D, Stubbs H, Lee DY, Singh A, Drew L, Haber DA,
Award from the Donald A Adam Comprehensive Melanoma Research Center (Moffitt Cancer Center) and the NIH/National Cancer Institute PSOC grant U54 CA143970-01.

Supplementary Information accompanies the paper on British Journal of Cancer website (http://www.nature.com/bjc)
Settleman J (2008) Elevated CRAF as a potential mechanism of acquired resistance to BRAF inhibition in melanoma. Cancer Res 68: 4853-4861 Pratilas CA, Taylor BS, Ye Q, Viale A, Sander C, Solit DB, Rosen N (2009) (V600E)BRAF is associated with disabled feedback inhibition of RAF-MEK signaling and elevated transcriptional output of the pathway. Proc Natl Acad Sci USA 106: 4519-4524

Rudin CM, Hann CL, Laterra J, Yauch RL, Callahan CA, Fu L, Holcomb T, Stinson J, Gould SE, Coleman B, LoRusso PM, Von Hoff DD, de Sauvage FJ, Low JA (2009) Treatment of medulloblastoma with Hedgehog pathway inhibitor GDC-0449. N Engl J Med 361: $1173-1178$

Sala E, Mologni L, Truffa S, Gaetano C, Bollag GE, Gambacorti-Passerini C (2008) BRAF silencing by short hairpin RNA or chemical blockade by PLX4032 leads to different responses in melanoma and thyroid carcinoma cells. Mol Cancer Res 6: $751-759$

Sawyers C (2004) Targeted cancer therapy. Nature 432: 294-297

Sharma A, Trivedi NR, Zimmerman MA, Tuveson DA, Smith CD, Robertson GP (2005) Mutant V599EB-Raf regulates growth and vascular development of malignant melanoma tumors. Cancer Res 65: 2412-2421

Smalley KS, Brafford P, Haass NK, Brandner JM, Brown E, Herlyn M (2005) Up-regulated expression of zonula occludens protein-1 in human melanoma associates with $\mathrm{N}$-cadherin and contributes to invasion and adhesion. Am J Pathol 166: $1541-1554$

Smalley KS, Contractor R, Haass NK, Kulp AN, Atilla-Gokcumen GE Williams DS, Bregman H, Flaherty KT, Soengas MS, Meggers E, Herlyn M (2007a) An organometallic protein kinase inhibitor pharmacologically activates p53 and induces apoptosis in human melanoma cells. Cancer Res 67: 209-217

Smalley KS, Contractor R, Haass NK, Lee JT, Nathanson KL, Medina CA, Flaherty KT, Herlyn M (2007b) Ki67 expression levels are a better marker of reduced melanoma growth following MEK inhibitor treatment than phospho-ERK levels. Br J Cancer 96: 445-449

Smalley KS, Flaherty KT (2009) Integrating BRAF/MEK inhibitors into combination therapy for melanoma. Br J Cancer 100: 431-435

Smalley KS, Haass NK, Brafford PA, Lioni M, Flaherty KT, Herlyn M (2006) Multiple signaling pathways must be targeted to overcome drug resistance in cell lines derived from melanoma metastases. Mol Cancer Ther 5: $1136-1144$

Smalley KSM (2003) A pivotal role for ERK in the oncogenic behaviour of malignant melanoma? Int J Cancer 104: 527-532

Tsai J, Lee JT, Wang W, Zhang J, Cho H, Mamo S, Bremer R, Gillette S, Kong J, Haass NK, Sproesser K, Li L, Smalley KS, Fong D, Zhu YL, Marimuthu A, Nguyen H, Lam B, Liu J, Cheung I, Rice J, Suzuki Y, Luu C, Settachatgul C, Shellooe R, Cantwell J, Kim SH, Schlessinger J, Zhang KY, West BL, Powell B, Habets G, Zhang C, Ibrahim PN, Hirth P, Artis DR, Herlyn M, Bollag G (2008) Discovery of a selective inhibitor of oncogenic B-Raf kinase with potent antimelanoma activity. Proc Natl Acad Sci USA 105(8): $3041-3046$

Wang Y, Van Becelaere K, Jiang P, Przybranowski S, Omer C, SeboltLeopold J (2005) A role for K-ras in conferring resistance to the MEK inhibitor, CI-1040. Neoplasia 7: 336-347

Wellbrock C, Karasarides M, Marais R (2004a) The RAF proteins take centre stage. Nat Rev Mol Cell Biol 5: 875-885

Wellbrock C, Ogilvie L, Hedley D, Karasarides M, Martin J, NiculescuDuvaz D, Springer CJ, Marais R (2004b) V599EB-RAF is an oncogene in melanocytes. Cancer Res 64: 2338-2342

Yauch RL, Dijkgraaf GJ, Alicke B, Januario T, Ahn CP, Holcomb T, Pujara K, Stinson J, Callahan CA, Tang T, Bazan JF, Kan Z, Seshagiri S, Hann CL, Gould SE, Low JA, Rudin CM, de Sauvage FJ (2009) Smoothened mutation confers resistance to a Hedgehog pathway inhibitor in medulloblastoma. Science 326(5952): 572-574 